\title{
Genetic status of the wood stork (Mycteria americana) from the southeastern United States and the Brazilian Pantanal as revealed by mitochondrial DNA analysis
}

\author{
I.F. Lopes ${ }^{1,3}$, A.M. Tomasulo-Seccomandi ${ }^{1,2}$, A.L. Bryan Jr. ${ }^{2}$, \\ I.L. Brisbin Jr. ${ }^{2}$, T.C. Glenn ${ }^{2,4}$ and S.N. Del Lama ${ }^{1}$ \\ ${ }^{1}$ Departamento de Genética e Evolução, \\ Universidade Federal de São Carlos, São Carlos, SP, Brasil \\ ${ }^{2}$ Savannah River Ecology Laboratory, University of Georgia, \\ Drawer E, Aiken, SC, USA \\ ${ }^{3}$ Departamento de Engenharia de Biossistemas, \\ Universidade Federal de São João Del-Rei, Campus CTAN, \\ São João Del-Rei, MG, Brasil \\ ${ }^{4}$ Department of Environmental Health Science, \\ University of Georgia, Athens, GA, USA \\ Corresponding author: I.F. Lopes \\ E-mail: iaraflopes@ufsj.edu.br
}

Genet. Mol. Res. 10 (3): 1910-1922 (2011)

Received December 16, 2010

Accepted April 5, 2011

Published August 30, 2011

DOI http://dx.doi.org/10.4238/vol10-3gmr1217

\begin{abstract}
The wood stork (Mycteria americana) is a colonial wading bird that inhabits the Neotropical region from the southeastern United States (US) to northern Argentina. The species is considered to be endangered in the US due to degradation of its foraging and breeding habitat. In other parts of its range, such as in the Brazilian Pantanal region, breeding populations of this species appear to be stable. We compared the levels of genetic variability and population structuring of the US and the Pantanal breeding populations using mitochondrial DNA (mtDNA) control region
\end{abstract}


sequences. Twenty-seven haplotypes were identified among 88 wood stork samples collected from eight breeding colonies in the US and eight in the Pantanal. Patterns indicative of heteroplasmy were observed in $35.3 \%$ of the mtDNA sequences that were examined. Significantly higher levels of haplotype diversity were observed in the Pantanal samples compared to those from the US, suggesting that during the last century, demographic declines or a recent evolutionary bottleneck reduced the levels of mtDNA variability of the US population. Analyses of genetic structuring revealed non-significant genetic differentiation between these regions, indicating that either the populations were only recently separated or that gene flow continues to occur at low levels. Haplotype network analysis indicated low current levels of gene flow between populations that were closely related in the past.

Key words: Ciconiiformes; Conservation genetics; Heteroplasmy; Demographic history; Population structuring; Waterbirds

\section{INTRODUCTION}

The wood stork (Mycteria americana) is the only member of its genus that inhabits the Neotropical region. Breeding colonies composed primarily of this species are formed annually in flooded wetland areas from the southeastern United States (US) to northern Argentina (Coulter et al., 1999). Although its range is extensive, most of what is known about wood stork biology comes from research carried out on the US breeding population (e.g., Coulter et al., 1999; Bryan Jr. et al., 2008). Studies on this species have been stimulated in part by its endangered status under US legislation (Brooks and Dean, 2008).

Similar to other species of storks that are regionally endangered due to habitat degradation (International Union for Conservation of Nature; IUCN, 2010), the US wood stork population decline recorded between 1930 and 1978 has been attributed to the loss of wetland habitats (USFWS, 1996; Coulter et al., 1999; Brooks and Dean, 2008). However, due to the wood stork's large range and the apparent demographic stability recorded over other Neotropical wetland areas, the species is classified as of "least concern" by the IUCN at the global level (IUCN, 2010). The breeding populations of wood storks in South America are apparently stable and have not undergone a significant decline (McCort and Coulter, 1991). Large breeding colonies of this species are abundant in the Brazilian Pantanal, which is one of the most extensive and biodiverse wetland areas in the world (Junk, 2003).

The application of evolutionary and molecular genetics data to guide conservation and management efforts has been successful for many endangered species in the wild and captivity. Mitochondrial DNA (mtDNA) has been used during the last 30 years as an important molecular marker to estimate genetic variability, population genetic structuring, phylogeographic patterns, and phylogenies in the context of conservation genetics (Ballard and Whitlock, 2004; White et al., 2008). Some of the characteristics that make mtDNA attractive for studying populations from an evolutionary perspective are its high mutation rate, predominantly uniparental (non-recombining) mode of inheritance, and rapid coalescence time. Using mtDNA data, inferences can be made concerning past and contemporary population structure 
from genealogical relationships among haplotypes (Avise, 2000). Given these properties, it is expected that mtDNA and nuclear markers will reveal different, but complementary, types of information (Ballard and Whitlock, 2004; White et al., 2008).

Previous comparisons of genetic variability and differentiation among wood stork colonies sampled in the US and Brazil have used nuclear DNA markers (Del Lama et al., 2002; Rocha et al., 2004). Analyses of these markers showed similar levels of genetic variability between the two regions using allozymes (Del Lama et al., 2002) and/or microsatellites (Rocha et al., 2004). These studies also suggested that, despite the considerable population decline suffered by the US breeding population, the levels of genetic variability in this population were not significantly reduced when compared to the stable Brazilian Pantanal population. Additionally, these comparative studies found only modest genetic differentiation between the US and Pantanal breeding populations.

Comparative analyses between the US and Pantanal breeding colonies based on mtDNA data have not been previously carried out. The purpose of this study was to evaluate the levels of genetic variability and structuring of the US and the Pantanal breeding populations using sequences from the mtDNA control region I (464 bp). Considering that mtDNA analysis can potentially reveal genetic signs of recent bottleneck events and that the Pantanal colonies have remained stable, whereas the US colonies have strongly declined, reduced levels of mtDNA genetic variability are expected in the US compared to the Pantanal population. Additionally, examination of mtDNA sequences through analysis of genealogical trees allowed us to make inferences related to both historical and contemporary processes that have shaped wood stork population structure.

\section{MATERIAL AND METHODS}

\section{Sampling and genotyping}

The US samples $(\mathrm{N}=40)$ included blood from wood stork nestlings collected between 1990 and 2002 from eight breeding colonies located in the US of Florida and Georgia (Figure 1; Table 2). Samples of blood from Pantanal nestlings $(\mathrm{N}=48)$ were collected between 1999 and 2003 from eight colonies located in the Brazilian States of Mato Grosso and Mato Grosso do Sul (Figure 1; Table 2). Samples of nestlings collected from different nests were chosen for the analyses; thus, they were all presumably unrelated.

Samples collected from nestlings in the US colonies were stored in lysis buffer (100 $\mathrm{mM}$ Tris-HCl, $\mathrm{pH}$ 8.0, $100 \mathrm{mM}$ EDTA, and 1\% SDS), and DNA was extracted using the diatomaceous earth (MUD) protocol (Davis et al., 2000). Blood samples from the Pantanal nestlings were collected using 3\% EDTA as anticoagulant, centrifuged to separate erythrocytes and frozen in liquid nitrogen; total genomic DNA was extracted using proteinase K digestion followed by phenol/chloroform/isoamyl alcohol isolation and ethanol precipitation (Sambrook et al., 1989).

Polymerase chain reaction (PCR) amplification of a fragments of mtDNA containing part of NADH dehydrogenase subunit 6 (ND6, $100 \mathrm{bp}$ ), tRNA-Glu (72 bp), and part of the mtDNA control region domain I (CRI, $292 \mathrm{bp}$ ) was performed using the primers WS-L36 (5'-TTCCTCCCAAATAACCATA-3') and WS-H601 (5'-CCTTGGCTGTGTGTACG-3'), which were designed based on clones of the entire wood stork mtDNA control region plus flanking sequences (ND6 and 12S) (Lopes, 2002). 


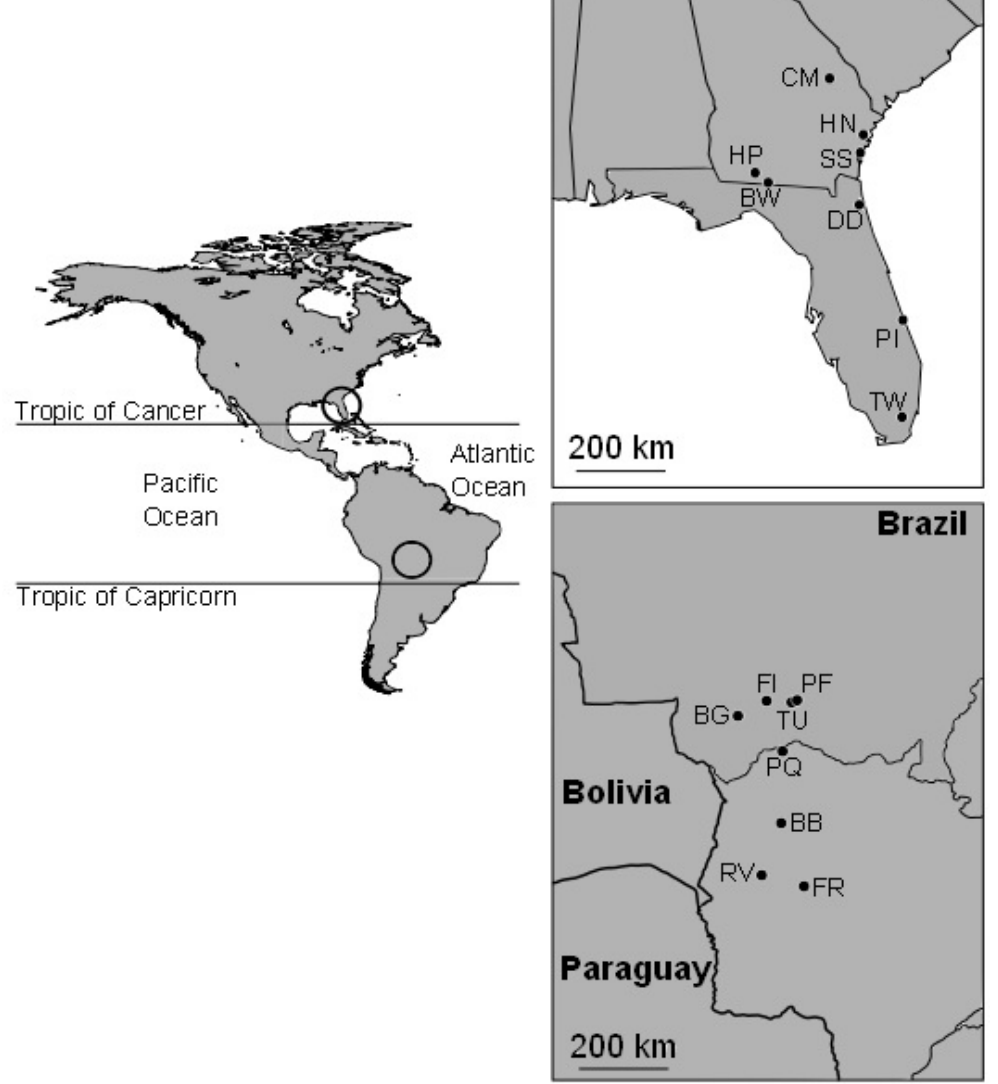

\section{United States}

Figure 1. Map of the Western Hemisphere showing the locations of the colonies sampled in the southeastern US and the Brazilian Pantanal. Abbreviations are given in Table 2.

Amplification of the control region sequence was performed in a final volume of 50 $\mu \mathrm{L}$ containing approximately $100 \mathrm{ng}$ genomic DNA, $10 \mathrm{mM}$ Tris- $\mathrm{HCl}, \mathrm{pH} 8.3,50 \mathrm{mM} \mathrm{KCl}$, $0.25 \mathrm{mM}$ dNTPs, $0.5 \mu \mathrm{M}$ of each primer, $2.5 \mathrm{mg} / \mathrm{mL}$ bovine serum albumin (BSA), $2.5 \mathrm{mM}$ $\mathrm{MgCl}_{2}$, and $1 \mathrm{U}$ Taq DNA polymerase. Cycling conditions were as follows: $5 \mathrm{~min}$ at $94^{\circ} \mathrm{C}$; five cycles of $20 \mathrm{~s}$ at $94^{\circ} \mathrm{C}, 20 \mathrm{~s}$ at $55^{\circ} \mathrm{C}$, and $20 \mathrm{~s}$ at $72^{\circ} \mathrm{C} ; 21 \mathrm{cycles}$ of $20 \mathrm{~s}$ at $94^{\circ} \mathrm{C}, 20 \mathrm{~s}$ at $55^{\circ} \mathrm{C}$ decreasing by $0.5^{\circ} \mathrm{C}$ per cycle, and $30 \mathrm{~s}$ at $72^{\circ} \mathrm{C} ; 10$ cycles of $20 \mathrm{~s}$ at $94^{\circ} \mathrm{C}, 20 \mathrm{~s}$ at $44.5^{\circ} \mathrm{C}$, and $30 \mathrm{~s}$ at $72^{\circ} \mathrm{C}$, and a final extension for $10 \mathrm{~min}$ at $72^{\circ} \mathrm{C}$. The PCR products were directly sequenced with an automated ABI Prism 3700 sequencer using the Big-Dye Terminator Cycle Sequencing kit (Perkin Elmer).

\section{Data analysis}

Sequences were aligned and visually verified using CODONCODE ALIGNER 1.5.2 
(CodonCode Corporation). Ambiguous bases potentially due to heteroplasmy, as revealed by overlapping nucleotides in electropherograms, were denoted using IUPAC code $(\mathrm{R}=\mathrm{A} / \mathrm{G}, \mathrm{Y}$ $=\mathrm{C} / \mathrm{T}, \mathrm{S}=\mathrm{G} / \mathrm{C}, \mathrm{W}=\mathrm{A} / \mathrm{T}, \mathrm{K}=\mathrm{G} / \mathrm{T}, \mathrm{M}=\mathrm{A} / \mathrm{C}, \mathrm{B}=\mathrm{C} / \mathrm{G} / \mathrm{T}, \mathrm{D}=\mathrm{A} / \mathrm{G} / \mathrm{T}, \mathrm{H}=\mathrm{A} / \mathrm{C} / \mathrm{T}, \mathrm{V}=\mathrm{A} / \mathrm{C} / \mathrm{G}$, and $\mathrm{N}=\mathrm{A} / \mathrm{T} / \mathrm{C} / \mathrm{G}$ ) (Appendix 1). Complete haplotype sequences are available from GenBank (Accession Nos. JF772187-JF772213).

As suggested by White et al. (2008), we used the PHASE 2.1 program (Stephens and Donnelly, 2003) implemented in DnaSP v 5 (Librado and Rozas, 2009) to examine the relationships of each haplotype and infer data without ambiguities. Haplotypes inferred by the coalescentbased Bayesian method implemented in PHASE 2.1 have proven to be as accurate as molecular cloning in reconstructing haplotypes from unphased data (Harrigan et al., 2008). Therefore, data were analyzed both by considering individuals as heteroplasmic and using haplotypes reconstructed by PHASE 2.1. Whether ambiguities were considered was indicated for each analysis.

Sequences were tested for neutrality using Tajima's D (Tajima, 1989) and Fu's Fs statistic (Fu, 1997) implemented in ARLEQUIN v 3.1 (Excoffier et al., 2006) and Fu and Li's F* and D* statistics (Fu and Li, 1993) in DnaSP. Tajimas's D and Fu's Fs tests were calculated considering individuals as heteroplasmic. Because analyses in DnaSP do not incorporate heteroplasmic data, the results of Fu and Li's $\mathrm{F}^{*}$ and $\mathrm{D}^{*}$ neutrality tests were based on reconstructed haplotypes.

Given that similar outcomes were obtained for genetic variability and population structuring analyses using data with or without ambiguous/heteroplasmic sites, we only presented data considering individuals as heteroplasmic to calculate these parameters. Haplotype diversity (h) and nucleotide diversity $(\pi)$ were estimated using ARLEQUIN. The non-parametric MannWhitney U-test was used to evaluate differences in the haplotype and nucleotide diversity values for colonies in these two regions. Partitioning of genetic variation among colonies and regions was investigated using F-statistic analysis of molecular variance (AMOVA; Excoffier et al., 1992) and pairwise $\mathrm{F}_{\mathrm{ST}}$ analyses as implemented in ARLEQUIN. A haplotype network was obtained using the TCS v 1.2 program (Clement et al., 2000) to make inferences about current and historic demographic processes shaping the genetic structure of wood stork populations.

\section{RESULTS}

Heteroplasmic patterns were quite clear (Appendix 1) and were confirmed by re-sequencing $20 \%$ of the individuals with heteroplasmic patterns. All patterns were consistent between the original and re-sequenced individuals, indicating that the putative heteroplasmy was not a result of simple sequencing errors or PCR artifacts.

A total of 27 haplotypes were identified among the 88 samples collected from the 16 breeding colonies from the US $(\mathrm{N}=8)$ and Pantanal $(\mathrm{N}=8)$ (Figure 2). The most common haplotype (H1, 52.3\%) was found in all colonies sampled in both regions. Haplotype H17 was observed in three US (TW, PI, and HP) and three Pantanal (PF, BG, and FI) colonies. Ten haplotypes were found exclusively in the US colonies, whereas 15 haplotypes were detected only in the Pantanal, with four of these being detected in at least two colonies (H11, H12, H14, and H26).

Neutrality tests showed no significant differences $(P>0.05)$ for any of the Pantanal samples (Table 1). The US samples deviated significantly from neutrality for the Fu and Li D* test $(\mathrm{P}<0.05)$ (Table 1). However, neutrality tests of the overall data indicated that the mtDNA region studied did not deviate significantly from expectations of the neutral mutation model for both geographic regions combined. 


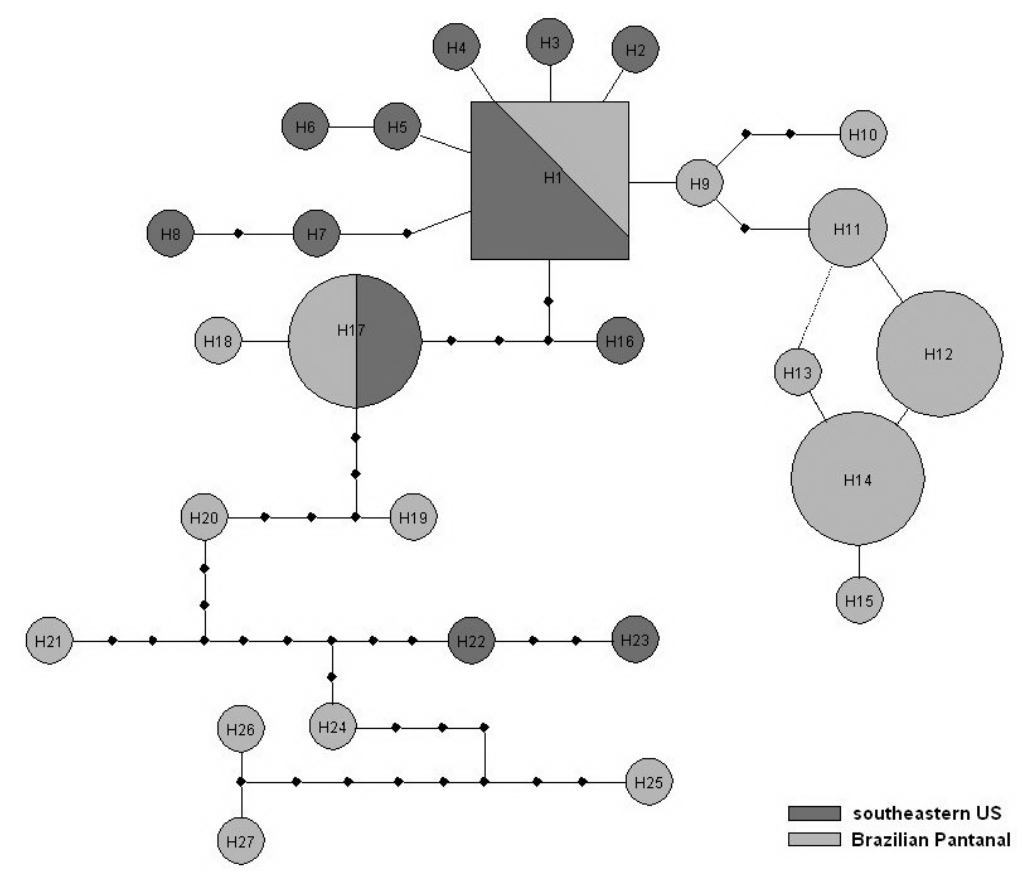

Figure 2. Estimated haplotype network for the mtDNA control region sequences of wood stork samples from the southeastern US and the Brazilian Pantanal. The square represents the most frequent haplotype (H1), and circles represent other less frequent sampled haplotypes (relative size of circles indicates the frequency of observation). Solid lines connecting haplotypes represent single nucleotide polymorphisms. Black dots indicate haplotype states that are necessary intermediates between observed haplotypes but that were not present in the sample.

Table 1. Neutrality tests applied to the US and Pantanal wood stork breeding populations.

\begin{tabular}{lcccc}
\hline & \multicolumn{3}{c}{ Neutrality tests } \\
\cline { 2 - 5 } Region sampled & $\mathrm{F}^{*}$ & $\mathrm{D}^{*}$ & $\mathrm{D}$ & $\mathrm{Fs}$ \\
\hline Southeastern US & 1.336 & $1.681^{+}$ & -1.365 & -3.079 \\
Brazilian Pantanal & -0.415 & 0.225 & 0.164 & -2.193 \\
\hline
\end{tabular}

${ }^{+} \mathrm{P}<0.05$

The levels of mtDNA variability are presented for each colony and region in Table 2. Overall, the haplotype diversity $(\mathrm{h}=0.822)$ and nucleotide diversity $(\pi=0.0044)$ of the Pantanal samples were greater than what was observed for the samples collected in the US colonies $(\mathrm{h}=0.546, \pi=0.0035)$. The non-parametric Mann-Whitney U-test showed significantly higher levels of haplotype diversity in the Pantanal colonies than in the US colonies (U $=6.000, \mathrm{P}=0.009)$. However, there was no significant difference between regions with respect to the nucleotide diversity $(\mathrm{U}=21.000, \mathrm{P}=0.463)$.

AMOVA and pairwise $\mathrm{F}_{\mathrm{ST}}$ analyses revealed non-significant genetic differentiation ( $\mathrm{P}$ $>0.05$ ) when the US and Pantanal breeding populations were compared, whether or not the data of each region were subdivided by colonies (Table 3 ). 
Table 2. Estimates of mtDNA control region diversity for each colony and the total sample collected from breeding wood storks in the southeastern US and the Brazilian Pantanal.

\begin{tabular}{|c|c|c|c|c|c|}
\hline Colony (code) & Geographical coordinates & $\mathrm{N}$ & No. hap & $h$ & $\pi$ \\
\hline Chew Mill Pond (CM) & $32^{\circ} 50^{\prime} \mathrm{N}, 82^{\circ} 06^{\prime} \mathrm{W}$ & 3 & 2 & 0.667 & 0.0000 \\
\hline Harris Neck $(\mathrm{HN})$ & $31^{\circ} 38^{\prime} \mathrm{N}, 81^{\circ} 17^{\prime} \mathrm{W}$ & 7 & 3 & 0.524 & 0.0012 \\
\hline Saint Simon (SS) & $31^{\circ} 16^{\prime} \mathrm{N}, 81^{\circ} 21^{\prime} \mathrm{W}$ & 7 & 3 & 0.524 & 0.0062 \\
\hline Heard's Pond (HP) & $30^{\circ} 53^{\prime} \mathrm{N}, 83^{\circ} 55^{\prime} \mathrm{W}$ & 5 & 4 & 0.900 & 0.0037 \\
\hline Blackwater (BW) & $30^{\circ} 41^{\prime} \mathrm{N}, 83^{\circ} 37^{\prime} \mathrm{W}$ & 1 & 1 & - & - \\
\hline Dee Dot (DD) & $30^{\circ} 12^{\prime} \mathrm{N}, 81^{\circ} 27^{\prime} \mathrm{W}$ & 4 & 1 & 0.000 & 0.0000 \\
\hline Pelican Island (PI) & $27^{\circ} 48^{\prime} \mathrm{N}, 80^{\circ} 26^{\prime} \mathrm{W}$ & 7 & 4 & 0.714 & 0.0070 \\
\hline Tamiami West (TW) & $25^{\circ} 45^{\prime} \mathrm{N}, 80^{\circ} 32^{\prime} \mathrm{W}$ & 6 & 3 & 0.600 & 0.0043 \\
\hline All southeastern US & - & 40 & 12 & 0.546 & 0.0035 \\
\hline Fazenda Ipiranga (FI) & $16^{\circ} 25^{\prime} \mathrm{S}, 56^{\circ} 36^{\prime} \mathrm{W}$ & 3 & 2 & 0.667 & 0.0072 \\
\hline Tucum (TU) & $16^{\circ} 26^{\prime} \mathrm{S}, 56^{\circ} 03^{\prime} \mathrm{W}$ & 9 & 5 & 0.833 & 0.0048 \\
\hline Porto da Fazenda (PF) & $16^{\circ} 27^{\prime} \mathrm{S}, 56^{\circ} 07^{\prime} \mathrm{W}$ & 8 & 6 & 0.928 & 0.0035 \\
\hline Baía de Gaíva (BG) & $16^{\circ} 39^{\prime} \mathrm{S}, 57^{\circ} 10^{\prime} \mathrm{W}$ & 7 & 6 & 0.952 & 0.0014 \\
\hline Piquiri (PQ) & $17^{\circ} 17^{\prime} \mathrm{S}, 56^{\circ} 21^{\prime} \mathrm{W}$ & 4 & 3 & 0.833 & 0.0000 \\
\hline Baía Bonita (BB) & $18^{\circ} 40^{\prime} \mathrm{S}, 56^{\circ} 26^{\prime} \mathrm{W}$ & 6 & 4 & 0.800 & 0.0007 \\
\hline Rio Vermelho (RV) & $19^{\circ} 36 \mathrm{~S}, 56^{\circ} 51^{\prime} \mathrm{W}$ & 4 & 3 & 0.833 & 0.0118 \\
\hline Fazenda Retirinho (FR) & $19^{\circ} 50^{\prime} \mathrm{S}, 56^{\circ} 02^{\prime} \mathrm{W}$ & 7 & 4 & 0.714 & 0.0072 \\
\hline All Brazilian Pantanal & - & 48 & 17 & 0.822 & 0.0044 \\
\hline
\end{tabular}

$\mathrm{N}=$ individuals sampled; No. hap = number of haplotypes; $h=$ haplotype diversity; $\pi=$ nucleotide diversity. The letter codes are used in Figure 1 to show colony locations.

Table 3. Analysis of molecular variance (AMOVA) results estimated from mtDNA control region sequences of wood stork samples collected in the US and Pantanal.

\begin{tabular}{llcc}
\hline Groupings & Source of variation & Percentage of variation & Fixation index \\
\hline US + Pantanal (no colony subdivision) & Between regions & 2.46 & $\mathrm{~F}_{\mathrm{ST}}=0.025$ \\
& Within regions & 97.54 & $\mathrm{~F}_{\mathrm{ST}}=0.009$ \\
US Colonies + Pantanal Colonies & Among colonies & 0.88 & $\mathrm{~F}_{\mathrm{CT}}=0.021$ \\
& Within colonies & 99.12 & $\mathrm{~F}_{\mathrm{SC}}=-0.003$ \\
US Colonies x Pantanal Colonies & Between regions & -0.10 & $\mathrm{~F}_{\mathrm{ST}}=0.018$ \\
& Among colonies/within regions & 98.15 & \\
& Within colonies & & \\
\hline
\end{tabular}

The haplotype network showed the presence of a high frequency common haplotypes (H1 and H17) present in both areas (Figure 2). Most of the haplotypes closely related to H1 were geographically restricted to the US colonies and to a clade that included only haplotypes sampled in the Pantanal region (H9 through H15). Other haplotypes distantly related to H17 were found mainly in the Pantanal samples.

\section{DISCUSSION}

\section{Detection of punctual heteroplasmy in wood storks}

Observations of double peaks in electropherograms are indicative of heteroplasmy, a condition characterized by the presence of more than one mtDNA lineage in the same individual (Kmiec et al., 2006; White et al., 2008). Although heteroplasmic mtDNA patterns are only rarely reported, White et al. (2008) suggested that heteroplasmy could be a default state given the high mutation rate of this molecule. However, mechanisms such as germline bottlenecks (Bergstrom 
and Pritchard, 1998) and the elimination of deleterious mutations by natural selection (Rispe and Moran, 2000) likely act to prevent high levels of mtDNA heteroplasmy in populations.

Most of the findings of heteroplasmy in birds have been related to mutation due to slippage processes generating length variation in control region sequences (Crochet and Desmarais, 2000), as observed in domain III of the mtDNA control region of wood storks (Lopes et al., 2006). In their study, by analyzing three pairs of siblings, Lopes et al. (2006) suggested that the observed length heteroplasmy was likely caused by mutation and maternally transmitted. The primers used in the present study were developed based on clones of the entire mtDNA control region of wood storks (Lopes, 2002). Because the amplification of long fragments and the use of species-specific primers usually minimize the likelihood of amplifying nuclear copies of mitochondrial genes (Ibargushi et al., 2006), we consider it unlikely that co-amplification of an ancient nuclear pseudogene occurred. Additionally, the nucleotide composition observed in our sequences (A: $30.4 \%$, C: $29.6 \%$, G: $13.1 \%$, and T: $26.9 \%$ ) was similar to what has been observed in domain I of other avian mtDNA control region sequences (A: 28.7\%, C: 25.3\%, G: 14.7\%, and T: 25.3\%; Baker and Marshall, 1997). Therefore, based on our analyses and the data reported by Lopes et al. (2006), the heteroplasmic pattern observed in the mtDNA sequences of wood storks can probably be explained as having been generated by mutation and then maternally transmitted. A likely mutational explanation for the heteroplasmic patterns observed in wood storks could be the duplication of mtDNA genes, as has been found in other species of birds, including the black-faced spoonbill (Platalea minor; Cho et al., 2009), which also belongs to the Ciconiiformes order.

\section{Genetic diversity}

A number of studies have demonstrated that genetic diversity can be lost as a consequence of genetic bottlenecks due to reductions in population size (Glenn et al., 1999; Beebee and Rowe, 2008). However, the effect of a population decline on the levels of genetic variability depends on its intensity and on the number of generations associated with the decline. Previous studies based on nuclear loci have not shown any significant difference in the levels of genetic variability between the US and the Pantanal wood stork populations (Del Lama et al., 2002; Rocha et al., 2004). Nevertheless, based on analyses of mtDNA sequences, the present study found a significant difference in the levels of haplotype diversity between these two populations. The apparently contradictory results shown by nuclear $v s$ mtDNA data are likely due to fundamental differences in the inheritance patterns and levels of recombination of nuclear and mitochondrial markers. The maternal inheritance pattern and absence of recombination that are characteristic of mtDNA cause this molecular marker to have a 4-fold lower effective population size compared to nuclear DNA; therefore, it is a more sensitive indicator of the loss of genetic variability than nuclear DNA markers (Avise, 2000). Additionally, haplotype diversity is strongly affected by the elimination of rare haplotypes, which frequently occurs after a bottleneck, whereas nucleotide diversity, which incorporates differences calculated base by base, is expected to show a less dramatic change in genetic diversity (Maruyama and Fuerst, 1985).

The pattern of genetic variability observed in wood stork populations may be linked to the well-recorded decline of the US breeding population $v s$ the apparent stability of breeding populations in Pantanal. South Florida wetlands previously supported the majority $(>75 \%)$ of the US wood stork colonies before the population decline (Coulter et al., 1999). Kushlan 
and Froghring (1986) reported that a $75 \%$ decline of the south Florida breeding population occurred over approximately 15 years (from 1967 to 1981-82), and the lowest annual total breeding population was estimated at 2500 breeding pairs in 1978 (USFWS, 1996). There are no generation time estimates for this species; however, considering the longevity in the wild (7-11 years) and age at first breeding (4 years) of these birds (Coulter et al., 1999), we estimate that the critical period of decline encompassed at least three generations. Although the intensity of the recorded bottleneck was quite significant demographically, thousands of individuals still survived when the lowest population numbers were observed. Thus, it is unlikely that lower levels of genetic variability would be detected in samples of the US population compared with the stable Pantanal population due to this historical bottleneck alone.

Alternatively, we suggest that limited mtDNA variation was present in the US wood stork population prior to the most recent demographic bottleneck. The lower levels of mtDNA variability of the US breeding population could also be explained by a recent colonization of the area or by a previous historic bottleneck, as suggested by Van Den Bussche et al. (1999). Recent paleoclimatological studies have found that a warmer and wetter climate than is currently observed in the southeastern US prevailed between 11,000 and 4500 years ago (LaMoreaux et al., 2009). Given that paleoclimatic events can cause profound changes in the levels of biodiversity associated with wetland areas (Junk, 2003) and that wood stork foraging and reproduction are highly dependent on water levels (Coulter et al., 1999), it is plausible that much of the southeastern US region might not have had appropriate conditions for breeding wood storks prior to 4500 years before the present. Finding haplotype networks with a common haplotype and most variants having a single or small number of mutational steps from the common haplotype are consistent with a severe historic bottleneck/ founding event and mutation accumulation thereafter. Additionally, the significant deviation from neutrality observed for the $\mathrm{Fu}$ and $\mathrm{Li} \mathrm{D}^{*}$ test of the US samples (Table 2) indicates an excess of low-frequency haplotypes, in accordance with the occurrence of population expansion or bottlenecks. Therefore, a previous historic demographic bottleneck followed by recent colonization could be responsible for the current low levels of mtDNA haplotype diversity. These alternative hypotheses could be tested by comparing the genetic variability levels in museum specimens sampled before the population decline with data presented here.

\section{Population structuring}

The detection of gene flow at the molecular level depends on several factors, including dispersal capabilities, levels of philopatry, habitat fragmentation, and time of isolation (Frankham et al., 2002; Beebee and Rowe, 2008). In the present study, mtDNA sequence analyses based on F-statistics (AMOVA and pairwise $\mathrm{F}_{\mathrm{ST}}$ ) showed a lack of genetic differentiation among breeding colonies within the US and the Pantanal, as well as between colonies located in these two regions. The same pattern has also been observed with allozyme and microsatellite data (Del Lama et al., 2002; Rocha et al., 2004). The arguments proposed to explain the absence of genetic structuring observed in these previous studies included the presence of intense gene flow, the low resolution power of allozymes, the low numbers of microsatellite loci used, and/or the occurrence of recent colonization followed by demographic expansion.

Contemporary gene flow could explain the observed patterns of mtDNA homogeneity based on F-statistics. Ecological and population dynamics factors, such as the potential to fly 
long distances and the high turnover rate of colonies (Frederick and Meyer, 2008), support this current gene flow hypothesis, at least among members of colonies in the same region. Ecological indications of gene flow among distant regions are scarce, but recent satellite tracking studies have suggested that there is at least some level of mixing between individuals from the US and Mexico/Central America (Bryan Jr. et al., 2008). Therefore, as previously hypothesized by Rocha et al. (2004), although direct migration of individuals between the US and Pantanal colonies may be unlikely, gene flow mediated by colonies located between these wetland areas might be possible due to the species' dispersal capabilities. Moreover, it should be noted that the statistical power of the analyses could be restricted by small sample sizes; therefore, these results should be interpreted with caution. Further investigations of genetic structure that include larger and more widespread samples could, thus, potentially reveal a different pattern of population structuring than that presented here.

Estimates of genetic structuring based on conventional F-statistics, as described above, primarily consider the variance of gene frequencies and do not incorporate any historical information (Templeton, 1998). Coalescence theory predicts that haplotypes located in the interior of a haplotype network should be ancestral to those haplotypes located more peripherally. Thus, the occurrence of the H1 and H17 haplotypes in both the US and Pantanal breeding populations (Figure 2) is more likely due to the retention of ancestral polymorphism than to contemporary gene flow between these areas. Additionally, the pattern observed in the main clade (H1-H18; Figure 2) is typical of low levels of contemporary gene flow between populations that were closely related in the past (Avise, 2000). Nevertheless, Templeton (1998) warned that gaps introduced by sampling design may impede the distinction between recurrent events, such as restricted gene flow, and historic events, such as past population fragmentation. Therefore, sampling and analyses of intermediate colonies between the US and the Pantanal should help to clarify the genealogical pattern found in this study.

\section{Conservation recommendations}

Given that low levels of genetic variability can result in reducing the time to extinction under changing environments, further investigations focusing on analyses of current and historical levels of genetic diversity in museum specimens are needed to guide future actions designed to assist in the recovery of the Endangered US breeding population. Given the rapid decline of wood storks in the US due to wetland degradation/loss and the higher genetic variability observed in the Pantanal populations, we recommend that Brazilian environmental agencies consider monitoring programs to gather information on recent demographic parameters, as well as expanding genetic analyses by including larger sample sizes and increasing the number of loci investigated. Such monitoring efforts will support management decisions related to the critically important Pantanal populations.

The absence of genetic structuring among the colonies sampled in both regions indicates that the colonies should not be considered as a population unit for conservation purposes, as has also been shown in previous genetic studies. This finding is in agreement with the observed high turnover rate of the wood stork breeding colonies (Frederick and Meyer, 2008), and these observations indicate that conservation management efforts focused exclusively on colony conservation are not likely to be effective. Further investigation should be undertaken to confirm that this pattern is indeed the case for this species in regions such as the Brazil- 
ian Pantanal. Meanwhile, the present data can be used to justify the immediate protection or recovery of habitats in key geographic areas that could support the maintenance of gene flow and, thus, the distribution of genetic diversity across the entire species range.

\section{ACKNOWLEDGMENTS}

The authors are grateful to the property owners who allowed access to the wood stork breeding colonies; A.E. Seccomandi, A.S. Cristino, A.T.B. dos Santos, C.D. Rocha, and M.A. Del Lama assisted with wood stork blood collection in the Pantanal; J.A. Rodgers Jr., R.A. Van Den Bussche, and B. Hylton provided samples from the US. Thanks also go to J.A.F. Monteiro and L. Rivaroli for drawing the map. We are grateful to CEMAVE/IBAMA for permission to handle birds and to collect biological material from wood storks in the Pantanal. Research supported by CNPq (\#140768/2002-5), FAPESP (\#2004/15205-8), and FAPEMIG (\#PRI-0010410). Additional support was provided by the U.S. Department of Energy Financial Assistance Award \#DE-FC09-96SR18546 to the University of Georgia Research Foundation/SREL.

\section{REFERENCES}

Avise JC (2000). Phylogeography: The History of Formation of Species. Harvard University Press, Cambridge.

Baker AJ and Marshall HD (1997). Mitochondrial Control Region Sequences as Tools for Understanding Evolution. In: Avian Molecular Evolution and Systematics (Mindell DP, ed.). Academic Press, San Diego, 51-83.

Ballard JW and Whitlock MC (2004). The incomplete natural history of mitochondria. Mol. Ecol. 13: 729-744.

Beebee TJC and Rowe G (2008). An Introduction to Molecular Ecology. 2nd edn. Oxford University Press, United Kingdom.

Bergstrom CT and Pritchard J (1998). Germline bottlenecks and the evolutionary maintenance of mitochondrial genomes. Genetics 149: 2135-2146.

Brooks, B and Dean T (2008). Measuring the biological status of the U.S. breeding population of Wood Storks. Waterbirds 31: 50-62.

Bryan AL Jr, Brooks WB, Taylor JD, Richardson DM, et al. (2008). Satellite tracking large-scale movements of wood storks captured in the Gulf Coast region. Waterbirds 31: 35-41.

Cho HJ, Eda M, Nishida S, Yasukochi Y, et al. (2009). Tandem duplication of mitochondrial DNA in the black-faced spoonbill, Platalea minor. Genes Genet. Syst. 84: 297-305.

Clement M, Posada D and Crandall KA (2000). TCS: a computer program to estimate gene genealogies. Mol. Ecol. 9: $1657-1659$.

Coulter MC, Rodgers JA Jr, Ogden JC and Depkin FC (1999). Wood Stork (Mycteria americana). In: The Birds of North America, No. 409 (Poole A and Gill F, eds.). The Birds of North America Inc., Philadelphia, American Ornithologists' Union, Washington, 1-28.

Crochet PA and Desmarais E (2000). Slow rate of evolution in the mitochondrial control region of gulls (Aves: Laridae). Mol. Biol. Evol. 17: 1797-1806.

Davis LM, Glenn TC, Elsey RM and Brisbin IL Jr (2000). Genetic Structure of Six Populations of American Alligators: A Microsatellite Analysis. In: Crocodilian Biology and Evolution. Surrey Beatty and Sons, Chipping Norton (Grigg GC, Seebacher and Ranklin CE, eds.). New South Wales, Australia, 38-50.

Del Lama SN, Lopes IF and Del Lama MA (2002). Genetic variability and level of differentiation among Brazilian pantanal Wood Stork populations. Biochem. Genet. 40: 87-99.

Excoffier L, Smouse PE and Quattro JM (1992). Analysis of molecular variance inferred from metric distances among DNA haplotypes: application to human mitochondrial DNA restriction data. Genetics 131: 479-491.

Excoffier L, Laval G and Schneider S (2006). Arlequin, Version 3.1: An Integrated Software Package for Population Genetics Data Analysis. Computational and Molecular Population Genetics Laboratory, Institute of Zoology, University of Berne. Available at [http://cmpg.unibe.ch/software/arlequin3]. Accessed March 19, 2007.

Frankham R, Ballou JD and Briscoe DA (2002). Introduction to Conservation Genetics. Cambridge University Press, Cambridge. 
Frederick PC and Meyer KD (2008). Longevity and size of wood stork (Mycteria americana) colonies in Florida as guides for an effective monitoring strategy in the Southeastern United States. Waterbirds 31: 12-18.

Fu YX (1997). Statistical tests of neutrality of mutations against population growth, hitchhiking and background selection. Genetics 147: 915-925.

Fu YX and Li WH (1993). Statistical tests of neutrality of mutations. Genetics 133: 693-709.

Glenn TC, Stephan W and Braun MJ (1999). Effects of a population bottleneck on whooping crane mitochondrial DNA variation. Conserv. Biol. 13: 1097-1107.

Harrigan RJ, Mazza ME and Sorenson MD (2008). Computation vs cloning: evaluation of two methods for haplotype determination. Mol. Ecol. Res. 8: 1239-1248.

Ibarguchi G, Friesen VL and Lougheed SC (2006). Defeating numts: semi-pure mitochondrial DNA from eggs and simple purification methods for field-collected wildlife tissues. Genome 49: 1438-1450.

IUCN (2010). IUCN Red List of Threatened Species. Version 2010.4. Available at [www.iucnredlist.org]. Accessed November 7, 2010.

Junk WJ (2003). Tropical/Subtropical Wetland Biodiversity: Status of Knowledge, Threats and Sustainable Management. In: Environmental Monitoring of Tropical and Subtropical Wetlands. Maun, Okavango Report Series (Bernard T, Mospele K and Ramberg L, eds.). Harry Oppenheimer Okavango Research Centre and University of Botswana, Botswana, 45-69.

Kmiec B, Woloszynska M and Janska H (2006). Heteroplasmy as a common state of mitochondrial genetic information in plants and animals. Curr. Genet. 50: 149-159.

Kushlan JA and Froghring PC (1986). The history of the southern Florida wood stork population. Wilson Bull. 98: 368386.

LaMoreaux HK, Brook GA and Knox JA (2009). Late Pleistocene and Holocene environments of the Southeastern United States from the stratigraphy and pollen content of a peat deposit on the Georgia Coastal Plain. Palaeogeogr. Palaeocl. 280: 300-312.

Librado P and Rozas J (2009). DnaSP v5: A software for comprehensive analysis of DNA polymorphism data. Bioinformatics 25: 1451-1452.

Lopes IF (2002). Diferenciação Genética entre Populações de Cabeça-Seca (Mycteria americana). Master's thesis, Universidade Federal de São Carlos, São Carlos.

Lopes IF, Brito RA, Henrique-Silva F and Del Lama SN (2006). Demographic history of wood stork (Mycteria americana) Brazilian Pantanal colonies revealed by mitochondrial DNA analysis. Gen. Mol. Biol. 29: 241-250.

Maruyama T and Fuerst PA (1985). Population bottlenecks and nonequilibrium models in population genetics. II. Number of alleles in a small population that was formed by a recent bottleneck. Genetics 111: 675-689.

McCort WD and Coulter MC (1991). Endangered Species Protection-the Wood Stork Example. In: Integrated Environmental and Management (Cairns J Jr and Crawford TV, eds.). Lewis Publishers, Michigan, 119-136.

Rispe C and Moran NA (2000). Accumulation of deleterious mutations in endosymbionts: Muller's ratchet with two levels of selection. Am. Nat. 156: 425-441.

Rocha CD, Del Lama SN and Regitano LA (2004). Lack of genetic structuring among tropical Brazilian wood stork populations and low genetic differentiation from North American population. Biotropica 36: 248-258.

Sambrook J, Fritsch EF and Maniatis T (1989). Molecular Cloning: A Laboratory Manual. 2nd edn. Cold Spring Harbor Laboratory Press, New York.

Stephens M and Donnelly P (2003). A comparison of Bayesian methods for haplotype reconstruction from population genotype data. Am. J. Hum. Genet. 73: 1162-1169.

Tajima F (1989). Statistical method for testing the neutral mutation hypothesis by DNA polymorphism. Genetics 123: 585-595.

Templeton AR (1998). Nested clade analyses of phylogeographic data: testing hypotheses about gene flow and population history. Mol. Ecol. 7: 381-397.

USFWS (U.S. Fish and Wildlife Service) (1996). Revised Recovery Plan for the U.S. Breeding Population of the Wood Stork. U.S. Fish and Wildlife Service, Atlanta.

Van Den Bussche RA, Harmon SA, Baker RJ, Bryan AL Jr et al. (1999). Low levels of genetic variability in North American populations of the wood stork (Mycteria americana). Auk 116: 1083-1092.

White DJ, Wolff JN, Pierson M and Gemmell NJ (2008). Revealing the hidden complexities of mtDNA inheritance. Mol. Ecol. 17: 4925-4942. 


\section{APPENDIX}

Appendix 1. Electropherograms showing heteroplasmic (double peaks) and homoplasmic patterns for the mtDNA control region sequences of wood stork samples from the southeastern US and the Brazilian Pantanal.
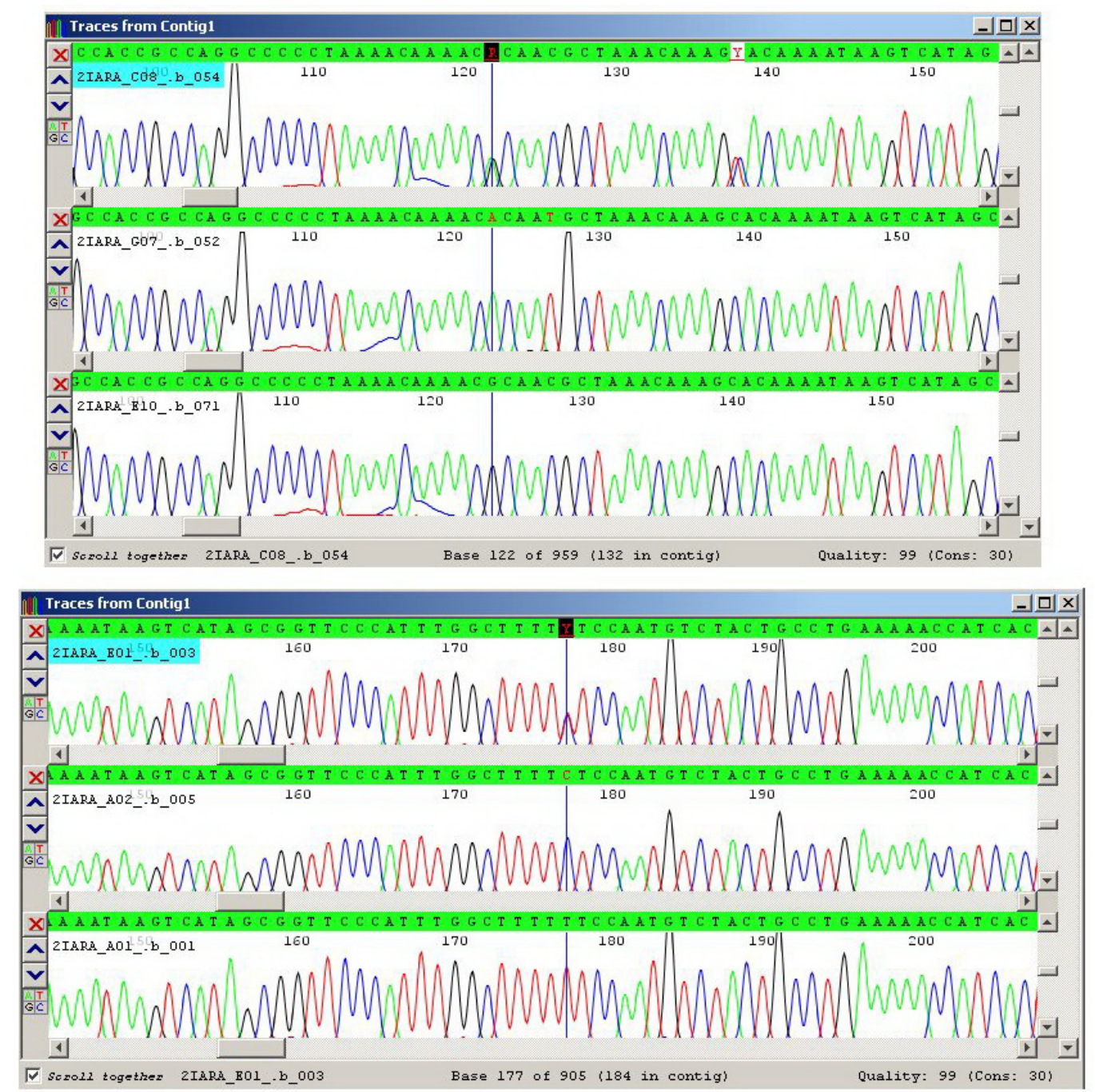